\title{
1A: Drug resistance in $H$. pylori - from basic mechanisms to clinical outcome
}

\section{A:01 DEGREES OF ANTIBIOTIC RESISTANCE IN H. PYLORI}

A. McLaren, C. Donnelly. Glaxo Wellcome Research, United Kingdom

Antibiotic resistance is a major cause of treatment failure in eradicating $H$. pylori and subsequent relapse of disease symptoms. Cost considerations have limited the number of studies comparing resistance pre and post treatments, and monitoring effect of resistance pre-treatment on eradication. What is the degree of resistance determining treatment failure?

This study was performed to measure three parameters 1) Minimum inhibitory concentration (MIC) of metronidazole (met) and clarithromycin (clar) against resistant strains 2) the numbers of resistant organisms within the total populations and 3) their stability, both in numbers and sensitivity over a range of subcultures. 10 strains comprising of 9 freshly obtained clinical isolates and one laboratory generated resistant strain were studied. 3 clinical strains were found to be resistant to both clar and met, only 2 of the clinical isolates were sensitive. MICs against met ranged from 31-250 $\mu \mathrm{g} / \mathrm{ml}$ for the resistant isolates, $2 \mu \mathrm{g} / \mathrm{ml}$ against the sensitive. Against clar resistant strains, MIC ranged from 31-250 $\mu \mathrm{g} / \mathrm{ml}$, as opposed to $0.03-0.13$ $\mu \mathrm{g} / \mathrm{ml}$ for sensitive isolates. One strain showed intermediate susceptibility, MIC $2 \mu \mathrm{g} / \mathrm{ml}$. There was wide variation in the numbers of organisms found to be resistant in the populations, ranging from 1 in $10^{5}$ to totally resistant. Sensitive strains acquired resistance in $<1$ in $10^{8}$. The numbers of organisms found to be resistant was stable over 10 sub-cultures for 8 isolates, but an increase in clar susceptibility was found in the intermediate strain and 1 isolate.

These studies have shown there are not just drug resistant and sensitive H. pylori strains. Emergence of resistance may not always be observed in strains that appear resistant. The numbers of resistant organisms within a population may be as important as the susceptibility of the isolates to antibiotics.

\section{A:02 INFLUENCE OF H. PYLORI RESISTANCE TO ANTIBIOTICS ON ERADICATION OUTCOME}

R.J. Adamek, S. Suerbaum ${ }^{1}$, B. Pfaffenbach, M. Wegener, W. Opferkuch ${ }^{1}$. Dept. of Medicine, St. Josef-Hospital, Germany; ${ }^{1}$ Dept. of Med. Microbiology, University of Bochum, Germany

Clarithromycin, metronidazole and amoxicillin are most potent and most frequently used antibiotics for cure of $H$. pylori infection. The aim of this study was to evaluate the primary and acquired resistance of $H$. pylori against these antibiotics and to elucidate their influence on $H$. pylori eradication.

195 patients with positive $H$. pylori status obtained by urease test, culture and histology who underwent $H$. pylori eradication therapy were included. In 172 patients $(88 \%) \mathrm{H}$. pylori could further be cultured for evaluation of primary antibiotic resistance. 50 patients received two-weeks dual therapy with amoxicillin $2000 \mathrm{mg}$ daily and 122 one-week modified triple therapy with clarithromycin $500-1000 \mathrm{mg}$ daily and metronidazole $1000-1500 \mathrm{mg}$ daily (A: $n=78$ ) or amoxicillin $2000 \mathrm{mg}$ daily and metronidazole 1000 $m g$ daily (B: $n=44)$, respectively. For acid suppression standard dosages of lansoprazole, omeprazole, pantoprazole bid and ranitidine $150 \mathrm{mg}$ tid were given. After therapy 36 patients were still $H$. pylori positive in culture, 20 after dual therapy and 16 after modified triple therapy (A: $n=7, B: n=9$ ). In 32 patients $H$. pylori could further be cultured for evaluation of acquired antibiotic resistance.

Primary $H$. pylori resistance was observed against metronidazole in 36 of 172 patients $(21 \%)$ and clarithromycin in 3 of $172(2 \%)$. Primary $H$. pylori resistance against amoxicillin was not noted. Patients with primary metronidazole resistance were successfully treated in combination with clarithromycin (8/9), but not with amoxicillin (0/4). None of the patients exhibited acquired amoxicillin resistance. In two patients acquired combined clarithromycin and metronidazole resistance was observed. In both modified triple therapy failured. Four patients treated with amoxicillin and metronidazole developed acquired metronidazole resistance. In all, $H$. pylori infection persisted after therapy.

The value of modified triple therapy with amoxicillin and metronidazole is significantly limited by primary and acquired metronidazole resistance. However, primary metronidazole resistance does not negatively influence treatment outcome in clarithromycin including modified triple therapy. In this regime primary clarithromycin sensibility seems to be meaningful. Acquired $H$. pylori resistances against clarithromycin and metronidazole are very rare, however they may become clinical significance in the future. $H$. pylori resistance against amoxicillin still is not present.

\section{A:03 HIGH CURE RATE OF H. PYLORI (HP) INFECTION BY ONE-WEEK THERAPY WITH OMEPRAZOLE (OME), METRONIDAZOLE (MET) AND CLARITHROMYCIN (CLA) DESPITE A NEGATIVE IMPACT BY MET RESISTANCE}

U. Peitz, A. Nusch, B. Tillenburg, M. Stolte ', G. Börsch, J. Labenz. Elisabeth Hospital, Essen, Germany; ${ }^{1}$ Institute of Pathology, Bayreuth, Germany

Purpose: In pilot and randomized controlled studies, the one-week triple therapy with OME $20 \mathrm{mg}$ bid, MET $400 \mathrm{mg}$ bid, and CLA $250 \mathrm{mg}$ bid (OMC) has gained consistently high HP cure rates of about $95 \%$. The influence of pretherapeutic in-vitro resistance of HP against MET and CLA on OMC efficacy was judged diversely in two studies and is investigated in this study in a larger number.

Methods: 94 patients (male $\mathrm{n}=55$, mean age 55 years; duodenal ulcer $n=29$, gastric ulcer $n=19$, functional dyspepsia $n=46$ ) completed this prospective study. The HP status was determined before and at least 4 weeks after OMC by histology and culture; HP resistance was assessed by E-Test (AB-Biodisk, Solna, Sweden).

Results: The pretherapeutic culture and testing of resistance were successful in 87 cases (93\%). MET resistance was found in 38 patients (44\%), including 2 patients $(2.3 \%)$ with CLA resistance as well. HP infection was cured in overall 86 cases (91\%), with MET sensitive strains in $100 \%$, with MET resistant strains in $82 \%$ (difference significant $p=0.002$ ). Side effects of OMC were stated mild, comprising mouth burning and/or loose stools in $22 \%$.

Conclusions: There was a significant impact of MET resistance on cure rate of OMC in HP infection. But despite a frequent MET resistance, the $82 \%$ cure rate in MET resistant strains still offers a good efficacy of the simple, save and cost effective OMC scheme.

\section{A:04 SIX YEARS RESISTANCE OF HELICOBACTER PYLORI TO MACROLIDES AND IMIDAZOLES}

E. De Koster, A. Cozzoli, C. Jonas, R. Ntounda, J.P. Butzler, M. Deltenre. Brugmann University Hospital, Brussels, Belgium

We reviewed the prevalence in our population of primary resistance (R) to macrolides (ML) and imidazoles (IMI) in 920 patients with newly diagnosed HP, who had not been treated for HP. Mean age 48.8 years; M/F $544 / 376(59.1 \%)$; age $\mathrm{M}(47.6)$ < age $\mathrm{F}(50.4)(\mathrm{p}<0.02)$. Results: Overall IMI R: $260 / 913=28.5 \%$; overall ML R: $35 / 582=6.0 \%(\mathrm{p}<0.0001)$. IMI R more frequent in females $(140 / 373,37.5 \%)$ than in males $(120 / 540$, $22.2 \%)(\mathrm{p}<0.0001)$; IMI R more frequent in Africans $(12 / 27,44.4 \%)$ than in Europeans $(167 / 617,27.1 \%)(p<0.02)$; IMI $R$ not different between Europeans $(167 / 617,27.1 \%)$ and Maghrebis $(68 / 222,30.6 \%)(p=0.31$, NS). Age pts with IMI R (46.3) lower than pts without IMI R (49.8) (p $<0.01$ ). IMI R not different for period 1990-1992 (128/436, 29.4\%) vs. 1993-1995 (122/476, 25.6\%) ( $\mathrm{p}=0.20, \mathrm{NS})$. ML R not different between male $(19 / 334,5.6 \%)$ and female $(16 / 248,6.4 \%)(\mathrm{p}=0.7018$, NS); no age difference between ML R (50.3) and ML Sensitive (47.8) $(p=0.43$, NS); no ethnic difference in ML R between Europeans, Africans, and Maghrebis. ML $R$ lower in 1990-1992 $(2 / 110,1.8 \%)$ than in 1993-1995 (33/471, $7.0 \%)(\mathrm{p}<0.05)$. ML $\mathrm{R}$ is stable within periods $1990-1992(2.2 \%, 0 \%$, $3.6 \%)$ and $1993-1995(6.0 \%, 8.7 \%, 6.5 \%)$. Conclusions: HP resistance to imidazoles is stable over the last 6 years at $28.5 \%$. Risk factors are female sex, younger age, and African ethnic origin. HP resistance to macrolides is less frequent than to imidazoles. It has increased almost fourfold since 1993 , but is stable since then at $7.0 \%$. 
1A:05 CORRELATION BETWEEN THE MICS OF METRONIDAZOLE ON HELICOBACTER PYLORI STRAINS AND THE OUTCOME OF A LANSOPRAZOLE-AMOXICILLIN-METRONIDAZOLE THERAPY

S. Bouchard ${ }^{1}$, C. Birac ${ }^{1}$, H. Lamouliatte ${ }^{2}$, S. Forestier ${ }^{3}$, F. Mégraud ${ }^{1}$. ${ }^{1}$ Hôpital Pellegrin, France; ${ }^{2}$ Hôpital St. André, Bordeaux, France;

${ }^{3}$ Laboratoire Takeda, Puteaux, France

Resistance to antibiotics is a major risk of treatment failure in all infections. Resistance of Helicobacter pylori to metronidazole has been reported to be high and there is a controversy regarding its clinical significance. Nevertheless, no data are presently available on the correlation between clinical efficacy of a triple therapy and MICs of the strains, the few existing data only classifying strains as susceptible or resistant without an indication of the true MIC. In a large study of a triple therapy, we have determined the MICs of $H$. pylori strains and the results have been correlated to the treatment outcome.

MICs were determined on pre-treatment strains by agar dilution on Wilkins Chalgren blood agar and read after $48 \mathrm{~h}$ incubation in a microaerobic atmosphere. The patients received the following treatment during 10 days: lansoprazole $(30 \mathrm{mg})$, amoxicillin $(1 \mathrm{~g}$ bid) and metronidazole $(500$ $\mathrm{mg}$ tid). Control of eradication was performed 4 to 6 weeks after the end of therapy. The tests used were histology, culture and PCR. A patient was considered cured if none of the tests were positive.

Ninety-five pre-treatment strains are available for analysis. Their MICs (mg/) were:

\begin{tabular}{llllllllll}
\hline 0.25 & 0.5 & 1 & 2 & 4 & 8 & 16 & 32 & 64 & 128 \\
\hline 1 & 9 & 27 & 22 & 15 & 3 & 1 & 4 & 10 & 3 \\
\hline
\end{tabular}

At the post-treatment control, $67 / 95$ strains were eradicated $(70 \%)$. The rate of eradication according to MIC was: $0.25-1 \mathrm{mg} / \mathrm{l}=30 / 37(81 \%)$; $2-8 \mathrm{mg} / \mathrm{l}=28 / 40(70 \%) ; 16-128 \mathrm{mg} / \mathrm{l}=9 / 18(50 \%)(\mathrm{p}=0.03$ for strains with MICs $\geq 16 \mathrm{mg} / \mathrm{l}$ versus the others). When amoxicillin is given as the only antibiotic, an eradication rate of $50 \%$ can be obtained. This is exactly what is observed when the MICs to metronidazole are $16 \mathrm{mg} / \mathrm{l}$ or higher. A dose-response effect was also found.

These data show that metronidazole resistance is clinically relevant and that for a triple therapy including amoxicillin and metronidazole, the break point of $8 \mathrm{mg} / \mathrm{l}$ is valid.

\section{A:06 ACTIVITY OF AMOXYCILLINE AND CLARITHROMYCINE ON HELICOBACTER PYLORI ATTACHED ON HELA CELLS OR ON MUCUS PRODUCING EPITHELIAL CELL LINE HT29/MTX}

B. Grignon, F. Dubin, M.F. Drilleau, J.L. Fauchère. University Hospital of Poitiers France

Antibiotic (AB) activity on Helicobacter pylori (Hp) may be reduced in the gastric environment. In this work, we studied the effect of the attachment on mucus producing cells, of $4 \mathrm{Hp}$ strains on their sensitivity to 2 widely used AB: amoxycilline (Amx.) and Clarithromycine (Cla.). The MICs of each $A B$ was the same for the 4 strains $(0.05 \mathrm{mg} / \mathrm{l}$ for $A \mathrm{mx}$ and $0.016 \mathrm{mg} / \mathrm{l}$ for Cla.). The 4 strains were similarly adherent to HeLa and HT29/MTX cell lines. As controlled by a spectrophotometric assay using alcian blue, HT29/MTX cells produced gastric mucus in a large amount while HeLa cells did not. Using a standard adherence assay, each bacterial strain was attached onto the 2 cell lines in normalised conditions. The cell monolayers were then incubated with $A B$ at concentrations of 2 MICs and then rinsed. Initial adherent bacteria and surviving bacteria were enumerated by viable count. The $\mathrm{AB}$ activity was evaluated by the log-reduction of viable count after contact with $A B$ (difference, in $\log _{10}$ between initial adhering bacteria and surviving adhering bacteria). The activity of Amx. varied from 2.02 to 2.70 with HeLa and from 2.07 to 2.76 with HT29/MTX. The activity of Amx. was similar for the 5 strains whatever the cell line used. The activity of Cla. varied from 2.44 to 3.00 with $\mathrm{HeLa}$ and from 0.24 to 3.00 with HT29/MTX. Regarding Cla., 3 strains were sensitive similarly on HeLa and on HT29/MTX while one strain was sensitive on HeLa (log reduction $=2.44$ ) and resistant on HT29/MTX (log reduction $=0.24)$. Although more strains are needed to confirm these results, the activity of Amx. on cell-adherent Hp seems identical with mucus-producing cells and non mucus-producing cells, while, for certain strains, the activity of Cla. is reduced when bacteria are attached on mucus producing cells.

\section{A:07 RELEVANCE OF METRONIDAZOLE RESISTANCE IN PREDICTING FAILURE OF OMEPRAZOLE, CLARITHROMYCIN AND TINIDAZOLE TO ERADICATE HELICOBACTER PYLORI}

P. Moayyedi, D.S. Tompkins ${ }^{1}$, P.L. Ragunathan ', A.T.R. Axon. Centre for Digestive Diseases, Leeds General Infirmary, UK; ${ }^{1}$ Dept. Public Health Medicine, Leeds, UK

Introduction: Omeprazole $250 \mathrm{mg}$ od/bd, clarithromycin $250 \mathrm{mg}$ bd and tinidazole $500 \mathrm{mg}$ bd for 7 days (OCT) is an effective regimen against $H$. pylori but the effect of metronidazole resistance on this regimen is unclear. Methods: $H$. pylori positive patients were prescribed OCT and cure of the infection was assessed by ${ }^{13} \mathrm{C}$-UBT 5 weeks after therapy. Metronidazole resistance was determined by the disc diffusion method. Samples were stored at $-70^{\circ} \mathrm{C}$ for re-culture and MIC assessment by E test. Results: 141 $H$. pylori infected patients were enrolled and the organism was successfully cultured in 119 cases. The incidence of metronidazole resistant strains was $121 / 141(38 \%)$. OCT was successful in 62/69 (90\%) patients harbouring fully sensitive strains of $H$. pylori compared with $42 / 45(93 \%)$ of patients with strains that were resistant to metronidazole alone $(p=1.0)$. MIC was assessed in 23 samples. A cut-off point of $>4 \mathrm{mg} / \mathrm{L}$ to define metronidazole resistance gave eradication rates of $57 \%$ in sensitive and $56 \%$ in resistant strains. If the cut-off was re-defined as $>32 \mathrm{mg} / \mathrm{L}$ then eradication rates were $70 \%$ in sensitive but only $30 \%$ in resistant strains. Conclusion: The disc diffusion method is not helpful in predicting OCT failure but the E test may be of value.

\section{A:08 RESISTANCE OF HELICOBACTER PYLORI TO CLARITHROMYCIN AND METRONIDAZOLE IN EASTERN FRANCE}

M.C. Conroy ${ }^{1}$, J.D. de Korwin ${ }^{2}$, A. Lozniewski ${ }^{1}$, M. Weber ${ }^{1}$.

${ }^{1}$ Laboratoire de Bactériologie, Hôpital Central, CHU, 54035 Nancy Cedex, France; ' ${ }^{1}$ Service de Médecine D, Hôpital Central, CHU, 54035 Nancy Cedex, France

Clarithromycin (C) and metronidazole (M) are major antibiotics used in triple therapies with acid antisecretory drugs. Increasing rate of resistance of $H$. pylori to $\mathrm{C}$ and $\mathrm{M}$ could be due to increasing usage of macrolides and 5-nitroimidazoles in the community. Primary resistance of $H$. pylori was studied in 38 consecutive strains isolated in 1994-95 from untreated dyspeptic patients (M/F ratio: 1.5; mean age: 44 years; range 27-80) with peptic ulcer $(n=9 ; 24 \%)$, gastric cancer $(n=2.5 \%)$ or non ulcer dyspepsia $(n=27 ; 71 \%)$. The MIC of $C$ and $M$ were determined by the agar dilution method using brain heart infusion agar medium supplemented with $10 \%$ horse blood and $1 \%$ polyvitex (BioMérieux). Inoculum was adjusted at $2 \mathrm{McF}$ and the plates were inoculated with a Steer's replicator (1 $\mu \mathrm{l} / \mathrm{spot}$ ). Resistances to C (MIC $>2 \mathrm{mg} / \mathrm{l}$ ) and to $\mathrm{M}$ (MIC $>8 \mathrm{mg} / \mathrm{l}$ ) were respectively found in 2 (5.3\%) (one peptic ulcer) and in $3(7.9 \%)$ (no peptic ulcer) of the isolates. Values of mode MIC, $\mathrm{MIC}_{50}$ and $\mathrm{MIC}_{90}$ were respectively $0.03,0.03$ and $0.5 \mathrm{mg} / 1$ for $C$ and $0.5,1$ and $4 \mathrm{mg} / 1$ for $\mathrm{M}$. Resistances of strains isolated from 7 patients $(18.4 \%)$ born in maghrebian countries were slightly different for $C(0 \%$ vs $6.5 \%)$ and $M(14.3 \%$ vs 6.5\%). Resistance rates to $C$ and $M$ seemed lower than those described in other french or belgian centers and encourage us to use $C+M$ combination for $H$. pylori eradication.

\section{A:09 A 5-YEAR SURVEY OF METRONIDAZOLE AND CLARITHROMYCIN RESISTANCE IN CLINICAL ISOLATES OF HELICOBACTER PYLORI}

H.X. Xia ', C.T. Keane ', C.A. O'Morain ${ }^{2}$. ' St. James's Hospital, Dublin 8, Ireland; ${ }^{2}$ Meath Hospital, Dublin 8, Ireland

This survey was carried out to determine whether and to what extent (if yes) the prevalence of $H$. pylori resistant strains in dyspeptic patients increased during past five years in the Irish capital city, H. pylori was cultured from antral biopsies. Susceptibility testing of the isolates to metronidazole

\begin{tabular}{llllll}
\hline Year & \multicolumn{3}{l}{ Antimicrobial Agents } & & \\
\cline { 2 - 3 } & \multicolumn{2}{l}{ Metronidazole } & & \multicolumn{2}{l}{ Clarithromycin } \\
\cline { 2 - 3 } \cline { 5 - 6 } & $\begin{array}{l}\text { No. of } \\
\text { isolates }\end{array}$ & $\begin{array}{l}\text { No. (\%*) of } \\
\text { resistance }\end{array}$ & & $\begin{array}{l}\text { No. of } \\
\text { isolates }\end{array}$ & $\begin{array}{l}\text { No. (\%) of } \\
\text { resistance }\end{array}$ \\
\hline 1991 & 217 & $69(31.8)$ & & ND & ND \\
1992 & 382 & $130(34.1)$ & & ND & ND \\
1993 & 339 & $121(35.7)$ & & 337 & $18(5.3)$ \\
1994 & 201 & $78(38.8)$ & & 209 & $12(5.7)$ \\
1995 & 160 & $74(46.3)$ & & 162 & $14(8.6)$ \\
Total & 1299 & $472(36.3)$ & & 708 & $44(6.2)$ \\
\hline
\end{tabular}

ND, not done; ${ }^{*} \mathrm{p}<0.05$ (chi-square test, $2 \times 5$ ). 
and clarithromycin was performed using validated disc diffusion tests. The subsequent isolates which were cultured from the same patients, but exhibited the same susceptibility as the original ones were excluded. The results were summarised in the table.

In conclusion, the prevalence of metronidazole resistance in clinical isolates of $H$. pylori increased significantly during the past 5 years, while an increase in the prevalence of clarithromycin resistance during the past 3 years was not statistically significant.

\section{A:10 COMPARATIVE IN VITRO ACTIVITY OF FAROPENEM AND OF KETOLIDES AGAINST RECENT BELGIAN CLINICAL ISOLATES OF HELICOBACTER PYLORI}

Y. Glupczynski ${ }^{1}$, S. Goutier ${ }^{2}$, C. Van den Borre ${ }^{2}$, A. Burette ${ }^{3}$, J.P. Butzler ${ }^{2} .^{1}$ André Vésale Hospital, Montigny-le-Tilleul, Brussels, Belgium; ${ }^{2}$ Brugmann Hospital, Brussels, Belgium; ${ }^{3}$ Nouvelle Clinique de la Basilique, Brussels, Belgium

The in vitro activities of faropenem (RU67655), an oral carbapenem, and of two ketolides (RU64004, RU66647), a new class of 14-membered ring macrolides, were evaluated comparatively to amoxicillin, clarithromycin, roxithromycin, tetracycline and metronidazole against 100 consecutive clinical isolates of $H$. pylori collected in 1995. In vitro susceptibility tests were performed by an agar dilution method using Columbia agar with $10 \%$ horse blood and a final inoculum of $\pm 10^{6}$ per spot. Plates were incubated for 3 days at $35^{\circ} \mathrm{C}$ in a microaerobic atmosphere. MIC values of amoxicillin, faropenem and clarithromycin were also determined against $10 \mathrm{H}$. pylori strains at three different $\mathrm{pH}$ values $(5.5,6.5, \& 7.5)$. Results were as follows:

\begin{tabular}{lllc}
\hline Antibiotics & $\begin{array}{l}\text { Range } \\
(\mu \mathrm{g} / \mathrm{ml})\end{array}$ & $\begin{array}{l}\mathrm{MIC}_{50} \\
(\mu \mathrm{g} / \mathrm{ml})\end{array}$ & $\begin{array}{l}\mathrm{MIC} 90 \\
(\mu \mathrm{g} / \mathrm{ml})\end{array}$ \\
\hline Faropenem & $<0.008-0.125$ & 0.008 & 0.015 \\
Amoxycillin & $<0.008-0.25$ & 0.015 & 0.03 \\
Tetracycline & $0.015-0.5$ & 0.06 & 0.25 \\
Metronidazole & $0.125->32$ & 1 & $>32$ \\
Clarithromycin & $<0.03-16$ & 0.03 & 0.06 \\
Roxithromycin & $<0.03-32$ & 0.06 & 0.125 \\
RU64004 & $<0.03-8$ & 0.06 & 0.25 \\
RU66647 & $<0.03-8$ & 0.06 & 0.25 \\
\hline
\end{tabular}

Overall, faropenem was found as the most active agent with MIC values usually one two-fold dilution lower than amoxycillin. On the other hand, metronidazole had the lowest intrinsic activity against $H$. pylori and the highest resistance rate ( $38 \%$ of the strains with a MIC $>8 \mu \mathrm{g} / \mathrm{ml})$. Clarithromycin appeared as the most active agent among the macrolides and the ketolides, but $8 \%$ of the strains were found resistant (MIC $\geq 2 \mu \mathrm{g} / \mathrm{ml}$ ). The two ketolides did not exhibit improved efficacy against macrolide-resistant strains, yet the MIC values for these drugs were usually 1 to 2 dilutions lower than for the macrolides. Interestingly, MICs of faropenem were not affected at all by testing at more acidic $\mathrm{pH}$ values. The remarkable in vitro activity of faropenem against $H$. pylori looks very promising and warrants further evaluation.

\section{A:11 WHICH FACTORS INFLUENCE ON THE SUCCESS OF "CLASSIC" TRIPLE THERAPY IN HELICOBACTER PYLORI ERADICATION?}

J.P. Gisbert, D. Boixeda, L. de Rafael, L. Moreno, C. Martín de Argila, F. Bermejo, C. Redondo. "Ramón y Cajal" Hospital, Madrid, Spain

Purpose: To study different factors influencing on the success of classic triple therapy in $H$. pylori eradication, specially previous therapy with omeprazol + amocycillin and metronidazole susceptibility.

Methods: Fifty-seven duodenal ulcer patients infected with $H$. pylori were prospectively studied. At endoscopy, biopsy specimens were taken from both gastric antrum and body (H\&E stain, Gram stain and culture). Classic triple therapy was administered (bismuth, tetracyclin and metronidazole). Patients were investigated endoscopically one month after completing therapy and repeat biopsy specimens from antrum and body were also obtained.

Results: $\mathrm{H}$. pylori eradication was achieved in 42 patients (74\%). In all cases but one compliance was complete. In multiple logistic regression analysis metronidazole susceptibility $(r=3.4 ; \mathrm{OR}=29.3)$ and previous therapy with omeprazol plus amoxycillin were the only variables which correlated with success in $H$. pylori eradication $(r=1.7 ; \mathrm{OR}=5.5)\left(\chi^{2}\right.$ model $=21 ; \mathrm{p}<0.001$ ). Additional variables (age, sex, smoking and histologic lesion) were no correlated with $H$. pylori infection. $H$. pylori was susceptible to metronidazole in 36 patients (79\%). Eradication rates for metronidazole-susceptible and metronidazole-resistant $H$. pylori isolates were $87 \%$ and $25 \%$, respectively $(p<0.001)$. When previous therapy with omprazole + amoxycillin had been administered the eradication rate was lower $(61 \%)$ than in patients without previous therapy $(82 \%)$.
Conclusion: Success of classic triple therapy in $H$. pylori eradication is higher when the organism is metronidazole-susceptible and lower when previous therapy with omeprazole + amoxycillin has been administered. This factor, although not fully elucidated, lends no support to choosing bismuth triple therapy when eradication therapy with omeprazole plus amoxycillin fails.

\section{A:12 LANSOPRAZOLE IN GASTRIC JUICE AND H. PYLORI}

M. Caselli ${ }^{1}$, R. Pedriali ${ }^{2}$, M. Ruina ${ }^{1}$, P. Gaudenzi ${ }^{1}$, L. Gallerani ${ }^{1}$, V. Alvisi ${ }^{~}{ }^{2}$ 'School of Gastroenterology, University of Ferrara, Italy; ${ }^{2}$ Institute of Chemistry, University of Ferrara, Italy

Lansoprazole, a new benzimidazole proton pump inhibitor, presents minimum inhibitory concentrations (MICs) against $\mathrm{H}$. pylori strains ranging from 3.13 to $12.5 \mu \mathrm{g} / \mathrm{ml}$ and, more recently, MICs90 of $2.5 \mu \mathrm{g} / \mathrm{ml}$ were reported. The quantity of lansoprazole, which is not metabolised in the hepatic first pass, is concentrated in gastric parietal cells. The highest plasma concentrations of lansoprazole are reached about 2 hours after administration, and appear to be dose-dependent reaching concentrations of about $1 \mu \mathrm{g} / \mathrm{ml}$ by using $60 \mathrm{mg}$ of lansoprazole (the maximum plasma concentrations of the drug appear to be much lower by using $30 \mathrm{mg}$ ). We determined lansoprazole concentration in gastric juice by High Liquid Chromatography (HPLC) 12 hours after a single oral administration around 10 p.m. of $15 \mathrm{mg}, 30 \mathrm{mg}$ and $60 \mathrm{mg}$ in 3 patients each. One $\mathrm{ml}$ of clear juice was submitted to solid-phase extraction (SPE) procedure. A SPE microcolumn $(3 \mathrm{ml}, 500 \mathrm{mg}$, RP-EP C 18) by International Sorbent Technology (U:K: CF8 8AU) was used Lansoprazole adsorbs quantitatively on solid phase $C$ 18. After washing out of gastric juice with redistilled water, a first elution was made with water-ethanol; lansoprazole is quantitatively eluted by $16 \mathrm{ml}$ of methanol. Lansoprazole peak was identified by spiking technique; it is well defined and has a retention time of 4.39 minutes. Lansoprazole concentration in gastric juice, 12 hours after a single night oral administration of $15 \mathrm{mg}$, was ranging from 0.3 to $0.5 \mu \mathrm{g} / \mathrm{ml}$, exponentially increased $1.2-2.0 \mu \mathrm{g} / \mathrm{ml}$ after administration of $30 \mathrm{mg}$ and further increased up to $2.9-3.4 \mu \mathrm{g} / \mathrm{ml}$ after a single administration of $60 \mathrm{mg}$, more than twice the maximum plasma concentration of the drug reached about 2 hours after administration of 30 and $60 \mathrm{mg}$. Lansoprazole seems to represent an interesting agent for eradication therapy trials.

\section{A:13 INFLUENCE OF TRIPLE THERAPY AGAINST HELICOBACTER} PYLORI ON INTESTINAL MICROECOLOGICAL BALANCE

D. Radun, A. Bühling ${ }^{1}$, U. v. Arnim, E. Bayerdörffer, W.A. Müller ${ }^{1}$, P. Malfertheiner. Dept of Gastroenterology, University of Magdeburg, Germany; ${ }^{1}$ Dept of Med. Microbiology, University of Magdeburg, Germany

Background: Previous studies have demonstrated that antibiotic treatment led to a decrease in the variety of intestinal microflora species and overgrowth of putrefactive bacteria such as Clostridia.

Aim: The aim of the present study was to investigate the intestinal microflora of patients infected with H. pylori (HP) before and after treatment with omeprazole, metronidazole and clarithromycin.

Methods: Stool samples collected from 59 patients with HP infection (13C urease breath test pos.) one day before treatment, day 8 and 4 weeks after therapy were cultivated on appropriate culture agars. Bacterial growth was determined qualitatively (bacterial species) and quantitatively (cfu/g feces).

Results: Eradication of HP resulted in a change of intestinal bacteria (see fig.), without a significant increase of putrefactive bacteria. We found a transient increase in colonization with yeasts. Four weeks after treatment the microflora resembled that of HP neg. persons.

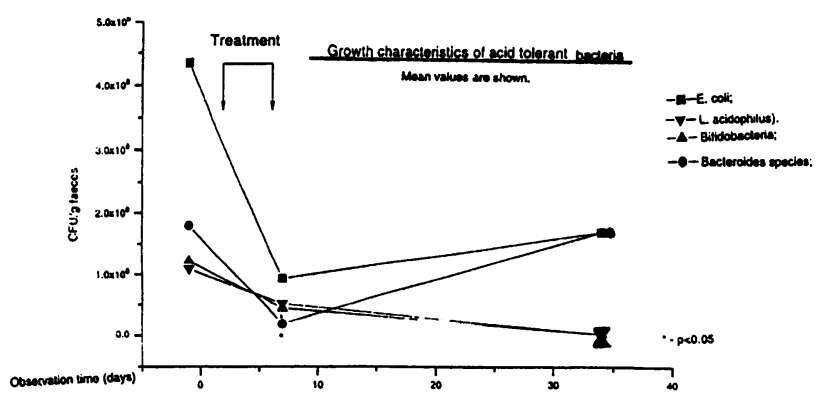

Conclusion: HP infection was associated with an overgrowth of acid tolerant bacteria and a decreased total number of species in feces. Eradication of HP led to a normalization rather than an increase in the variety of intestinal microflora without an overgrowth of putrefactive bacteria as reported previously. 
1A:14 OMEPRAZOLE WITH OR WITHOUT AMOXICILLIN ALTERS THE HUMAN GASTRIC MUCOSAL MICROFLORA IN PATIENTS WITH H. PYLORI INFECTION

I. Adamsson, C. Edlund, R. Seensalu, S. Sjöstedt, C. Stark, C.E. Nord. Karolinska Institute, Huddinge University Hospital, Stockholm, Sweden

Background: The ecological effects on the gastric microflora of acid inhibition alone or in combination with amoxicillin treatment in the presence of $H$. pylori infection were studied.

Methods: 28 dyspeptic patients with $H$. pylori infection (CLO, PCR, histology) were included. 14 patients were treated with omeprazole capsules $20 \mathrm{mg}$ and amoxicillin capsules $1000 \mathrm{mg}$ twice daily for 14 days (ome-amox), and 14 patients with omeprazole capsules $20 \mathrm{mg}$ and placebo twice daily for 14 days (ome-plac). Biopsy specimens from antrum and corpus were collected before, during and after treatment, and inoculated on agar media. The biopsies were incubated aerobically and anaerobically. The different colony types were counted and identified to genus level by morphological, biochemical and gas chromatographic analysis. H. pylori was cultured on Brucella agar and supplemented Brucella agar for 5 days in microaerophilic atmosphere (Campy Pak ${ }^{\circledR}$ ).

Results: H. pylori was cultured in 25 patients, 22 of which also harboured a normal mucosal microflora (streptococci, micrococci, neisseria, haemophilus, enterobacteria, peptostreptococci, actinomyces, veillonella and bacteroides). The number of commensal microorganisms increased significantly in the ome-plac group during treatment, and a minor increase was also noticed in the ome-amox group. The number of $H$. pylori significantly decreased during treatment, most pronounced in the ome-amox group. On day 42 , the normal mucosal flora returned to pretreatment levels in both treatment groups. Four weeks after treatment $H$. pylori was eradicated in 54\% of the patients in the ome-amox group and in no patients in the ome-plac group.

Conclusion: There was an inversed relationship between the number of normal microorganisms and the number of $H$. pylori in the gastric mucus layer during omeprazole treatment, with or without amoxicillin, in patients with $H$. pylori infection.

\section{A:15 AQUIRED AND PERSISTENT MACROLIDE RESISTANCE IN PATIENTS TREATED WITH CLARITHROMYCIN}

K. Hultén, L. Engstrand. Depts. of Clinical Microbiology and Cancerepidemiology, University Hospital, Uppsala, Sweden

Introduction The increased use of macrolides in treatment of $H$. pylori infection contributes to the emergence of resistance and cross-resistance in this group of antibiotics. It has been suggested that such resistance is of limited clinical importance as resistant strains revert when exposure to the drug is withdrawn. We examined $H$. pylori strains from patients with persistent infection after combination treatment with high-dose clarithromycin to challenge this hypothesis.

Material and methods $H$. pylori strains were cultured from 7 patients with persistent $H$. pylori infection before and after combination treatment with clarithromycin $(n=4)$ or clarithromycin + tetracycline $(n=3)$. The sensitivity of these strains to tetracycline, clarithromycin, erythromycin and azithromycin was evaluated with E-test (Biodisk AB, Sweden). In addition, the MIC-values for clarithromycin was estimated with an agar dilution method. The resistant strains were subcultured on agar plates 20 times to examine the stability of the aquired resistance. After 10 and 20 subcultivations, MIC-values were estimated by both agar dilution and E-test.

Results The seven patients were sensitive to tetracycline $(0.25-1.0$ $\mu \mathrm{g} / \mathrm{ml}$ ) before and after treatment. All patients were sensitive to macrolides before treatment with MIC-values of $<0.016 \mu \mathrm{g} / \mathrm{ml}$ (E-test and agar dilution). After treatment with clarithromycin these strains showed MICvalues between 8 and $256 \mu \mathrm{g} / \mathrm{ml}$ in the E-test and 16 and $128 \mu \mathrm{g} / \mathrm{ml}$ with the agar dilution method. Furthermore these strains were resistant to both azithromycin and erythromycin (>256 $\mu \mathrm{g} / \mathrm{ml}$, E-test). Subculture of strains on agar plates did not result in an in vitro reversion of the resistance pattern.

Conclusion The extented use of clarithromycin will evidently give raise to resistance and macrolide cross-resistance. In this study the bacteria remain resistant which contradicts previous results. Even though treatment regimens with clarithromycin gives high eradication rates, the risk of wide-spread macrolide resistance must be taken into account.
1A:16 CLARITHROMYCIN-RESISTANT HELICOBACTER PYLORI PREVALENCE OF 235 rRNA GENE MUTATIONS IN FROM EUROPEAN AND ARGENTINIAN CLINICAL TRIALS

G.G. Stone ${ }^{1}$, D. Shortridge ${ }^{1}$, R.K. Flamm ${ }^{1}$, D. Stamler ${ }^{2}$, J. Versalovic ${ }^{3}$, J. Beyer ${ }^{1}$, A.T. Ghoneim ${ }^{4}$, D.Y. Graham ${ }^{3}$, S.K. Tanaka ${ }^{1} .{ }^{1}$ Anti-Infective Research Division, Abbott Laboratories, Abbott Park, IL USA; ${ }^{2}$ Abbott International, Abbott Laboratories, Abbott Park, IL USA; ${ }^{3}$ VAMC and Baylor College of Medicine, Houston, TX USA; ${ }^{4}$ St. James University Hospital, Leeds, UK

Helicobacter pylori has been recognized as an etiological agent of chronic gastritis and duodenal ulcers in humans. For treatment of an $H$. pylori infection, clarithromycin is a component of several successful combination therapies. Although pretreatment clarithromycin resistance rates are low, transition mutations in the peptidyltransferase loop of 23S rRNA have been associated with resistance. We developed a rapid PCR-oligonucleotide ligation assay to screen for the presence of point mutations that confer resistance to macrolides. These mutants were screened for the presence of A-to-G point mutations cognate to 2058 and 2059 of domain $V$ in the $23 \mathrm{~S}$ rRNA gene of Escherichia coli. We screened a total of $51 \mathrm{H}$. pylori isolates from 2 clinical trials. Of the 51 isolates, 19 were isolated from patients prior to treatment and found to be susceptible to clarithromycin. An additional 3 isolates from patients prior to treatment were resistant to clarithromycin. The remaining 29 isolates were from patients after treatment. Of the 29 posttreatment isolates, 26 were resistant to clarithromycin and 3 were susceptible. In our screening assay, 17 of $29(59 \%)$ resistant isolates contained mutations at 2058 and 12 of $29(41 \%)$ isolates contained mutations at 2059. We obtained 3 isolates that contained A-to-C mutations at 2058 where previously only A-to-G mutations at either 2058 or 2059 had been reported for clarithromycin resistance in $H$. pylori. All 22 clarithromycin-susceptible isolates of $H$. pylori screened were wildtype in our assay. In addition, minimum inhibitory concentrations to clarithromycin were determined by agar dilution and correlated with the mutations. MICs of clarithromycin ranging from $64 \mu \mathrm{g} / \mathrm{ml}$ to $\geq 128 \mu \mathrm{g} / \mathrm{ml}$ were associated with mutations at 2058 in 16 of $17(94 \%)$ isolates. MICs ranging from $8 \mu \mathrm{g} / \mathrm{ml}$ to $\leq 32$ $\mu \mathrm{g} / \mathrm{ml}$ were associated with mutations at 2059 in 10 of $12(83 \%)$ isolates. Our data indicate that greater resistance to macrolides occurs as a result of a mutation at position 2058 compared to position 2059.

\section{A:17 MECHANISM OF CLARITHROMYCIN RESISTANCE IN CLINICAL ISOLATES OF HELICOBACTER PYLORI}

Y.J. Debets-Ossenkopp, M. Sparrius, J.G. Kusters, J.J. Kolkman. C.M.J.E. Vandenbroucke-Grauls Vrije Universiteit, Amsterdam, the Netherlands

The macrolide clarithromycin has been successfully used in eradication therapy of Helicobacter pylori. In a clinical trial in our hospital, eradication of $H$. pylori failed in fifteen out of seventythree patients treated with a combination of clarithromycin and ranitidine. In eleven of these fifteen patients failure was due to clarithromycin resistance. In one patient the infecting strain was already resistant at the onset of treatment, while in the remaining ten clarithromycin resistance developed during therapy. Besides a simultaneous resistance to other macrolides as erythromycin and azithromycin these isolates had also become resistant to lincosamide and streptogramin type-B antibiotics. RAPD and RFEL analysis on the isolates of these ten patients showed a close genetic relatedness between pre- and post-treatment isolates, indicating that resistance was the result of selection of variants of the infecting strain rather then infection with an exogenous resistant strain. Erythromycin resistance methylases were not detected in these paired isolates, but nucleotide sequence comparisons revealed that al resistant isolates had a single base pair mutation in the 23S rRNA. Since apparently a single point mutation leads to coresistance to macrolides, lincosamide and streptogramin type-B antibiotics at such high frequencies the use of clarithromycin as a single antibiotic in eradication regimens for Helicobacter pylori infection should be avoided.

\section{A:18 CLONING OF A METRONIDAZOLE-RESISTANCE LOCUS FROM HELICOBACTER PYLORI}

A. Goodwin, S. Veldhuyzen van Zanten, P.S. Hoffman. Dalhousie University, Halifax, Nova Scotia, Canada

Resistance to metronidazole (MtzR) is the major determinative factor in failure of triple therapy to eradicate Helicobacter pylori $(H p)$ infection. We have investigated the basis for Mtz resistance using isogenic strains of $H p . \mathrm{Mtz}^{\mathrm{r}}$ strains, when grown in the presence of Mtz, express no detectable pyruvate or $\alpha$-ketoglutarate oxidoreductase activity. The activities of these enzymes are required for reduction of $\mathrm{Mtz}$ to the biologically active hydroxylamine derivative. In addition, there are other enzymatic activities that may contribute to drug resistance including expression of the glyoxylate bypass. Since MtzR can be acquired via natural transformation, 
we have employed a similar strategy to clone genes associated with MtzR. A genomic cosmid library of $\mathrm{Mtz}^{\mathrm{r}}$ strain HP439 was constructed in Lorist6. Over 800 clones were screened in batches of 96 by electroporating cosmid DNA into $\mathrm{Mtz}^{\mathrm{s}} \mathrm{Hp}$ strains. From two batches yielding positive results, one clone was identified for which cosmid DNA, when transformed into $\mathrm{Mtz}^{\mathrm{s}}$ strains HP500, HP1134, and HP950, permitted growth on brucella agar containing $20 \mu \mathrm{g} / \mathrm{ml}$ of Mtz. Restriction analysis of the 3D7 clone identified a $2 \mathrm{kbp}$ DNA fragment that when transformed into $\mathrm{Mtz}^{\mathrm{s}}$ strains conferred Mtz resistance. The results of this study indicate that a single genomic locus may be responsible for Mtz resistance and that through recombination, a locus required for Mtz toxicity may be inactivated.

\section{A:19 23S rRNA GENE MUTATIONS IN H. PYLORI: THE A2058G MUTATION IS MOST PREVALENT AND ASSOCIATED WITH HIGH LEVEL CLARITHROMYCIN RESISTANCE}

J. Versalovic ${ }^{1}$, M. Osato ${ }^{1}$, K. Spakovsky ${ }^{1}$, M.P. Dore ${ }^{1}$, R. Reddy ${ }^{1}$, G.G. Stone ${ }^{2}$, D. Shortridge ${ }^{2}$, R.K. Flamm ${ }^{2}$, S.K. Tanaka ${ }^{2}$,

D.Y. Graham '. ' Baylor College of Medicine, Houston, USA; ${ }^{2}$ Abbott

Laboratories, Abbott Park, USA

Single base substitutions in the $H$. pylori 23S ribosomal RNA (rRNA) gene have been associated with macrolide resistance. To assess the relative prevalence of two adjacent transition mutations, A2058G or A2059G, a larger study that included 59 clarithromycin resistant $H$. pylori isolates from 59 individual U.S. or Canadian patients was performed. Clarithromycin resistance (MIC $>2 \mu \mathrm{g} / \mathrm{ml}$ ) phenotypes were determined by $\mathrm{E}$ tests. Molecular analyses were performed by rapid (within one hour) alkaline detergent-based cell lysis and diagnostic restriction digestions of $H$. pylori 23S rDNA PCR amplicons. The most prevalent mutation was A2058G (52.5\%); $39 \%$ of isolates contained the A2059G mutation and $8 \%(n=5)$ of isolates lacked either mutation. The A2058G mutation was significantly more likely to occur in isolates with MICs exceeding $64 \mu \mathrm{g} / \mathrm{ml}(68 \%$ vs. $31.6 \%$ with the $\mathrm{A} 2059 \mathrm{G}$ mutation, $\mathrm{p}=0.01$ ). The vast majority $(83.9 \%)$ of isolates with the A2058G mutation had MICs exceeding $64 \mu \mathrm{g} / \mathrm{ml}$. The high frequency and the high level of resistance conferred by the A2058G mutation may reflect a greater probability of treatment failure. In areas where macrolides are commonly used, the new method should allow rapid analysis of resistance and may be used to design appropriate treatment regimens. The combination of rapid cell lysis and restriction digestion of DNA affords the possibility of mutation detection within 24 hours from the time of biopsy.

\section{A:20 HELICOBACTER PYLORI RESISTANCE TO MACROLIDES. CONFIRMATION OF POINT MUTATION AND DETECTION BY PCR-RFLP}

A. Occhialini ${ }^{1}$, M. Urdaci ${ }^{2}$, F. Doucet-Populaire ${ }^{3}$, H. Lamouliatte ${ }^{4}$, C. Bébéar ${ }^{1}$, F. Mégraud ${ }^{1} .{ }^{1}$ Hôpital Pellegrin, ${ }^{2}$ University of Bordeaux I, Bordeaux; ${ }^{3}$ CHU Pitié Salpétrière, Paris; Hôpital Mignot, Le Chesnay; ${ }^{4}$ Hôpital St. André, Bordeaux, France

Resistance of Helicobacter pylori to macrolides is a major cause of treatment failure of eradication therapies. A princeps work based on U.S. strains showed that this resistance was due to a point mutation on the gene coding for the 23S ribosomal RNA of $H$. pylori. Our goal was to extend this work using European strains, to test the consequence of this mutation on erythromycin binding to $H$. pylori ribosomes, and to find a quick method to detect this mutation. The reference strain CIP 101260 and 7 pairs of $H$. pylori strains were used, the parent strain being susceptible to macrolides, and a second strain having acquired resistance in vivo during clarithromycin treatment. The identity of the strains was confirmed by RAPD using 2 primers. The MIC values were measured by $E$ test and agar dilution method. Amplification was carried out on the peptidyl transferase loop region of the gene coding for the 23S rRNA using appropriate primers in order to confirm the presence of the mutations 2058, 2059 and 2611 previously described. The amplified products were sequenced. Erythromycin binding was tested on purified ribosomes isolated from one pair of strains using ${ }^{14} \mathrm{C}$ labelled erythromycin.

A point mutation was found on resistant strains at position 2058 ( 3 cases) and 2059 (4 cases) but never on the opposite DNA fragment of domain $\mathrm{V}$ of the gene. The mutation was $\mathrm{A} \rightarrow \mathrm{G}$ in all except one case $(A \rightarrow C)$ in position 2058. Erythromycin binding increased in a dose dependent manner for the susceptible strain but not for the resistant one. Using Bsal and $B b s I$ restriction enzymes on the amplified products, we could confirm the mutations in positions 2059 and 2058, respectively.

In conclusion, the same mutations as previously found were present in European strains. This mutation correlates with a decreased uptake of macrolide by ribosomes. Finally the mutation could be detected without sequencing by performing PCR-RFLP using appropriate restriction enzymes.

\section{A:21 RESISTANCE OF $H$. PYLORI TO METRONIDAZOLE AND MACROLIDES}

E. Rożynek, D. Dzierżanowska, D. Celińska-Cedro, A. Gzyl, J. Socha. The Children's Memorial Health Institute, Warsaw, Poland

One of the most frequent scheme of treatment of $\mathrm{H}$. pylori infections is triple regimen with metronidazole, amoxicillin and bismuth salts or omeprazole. The aim of our study was the determination of primary resistance of $104 \mathrm{H}$. pylori strains isolated from children to amoxicillin, tetracycline, erythromycin, clarithromycin, ciprofloxacin and metronidazole. Activity of tested antibiotics (MIC) was determined on Muller-Hinton agar supplemented with $7 \%$ horse blood by use of E-test kit. Inoculum of tested strains equivalent to no $1 \mathrm{McFarland}$ standard was used. The plates were incubated for 4 days at $37^{\circ} \mathrm{C}$ in microaerophilic conditions. Strains resistance to metronidazole were typed by PCR-RFLP and RAPD methods. Fifty eight $H$. pylori strains (56\%) were resistant to metronidazole. Analysis of resistance patterns have shown that eighteen strains were resistant to metronidazole, erythromycin and clarithromycin simultaneously. High percentage $(40 \%)$ of metronidazole-resistant strains before treatment in group of 50 children treated with bismuth salts, metronidazole and amoxicillin was observed. H. pylori clinical isolates resistant to metronidazole isolated before and after specific treatment showed identical restriction patterns. Cross-resistance between macrolide antibiotics strongly suggests the necessity of determination of sensitivity of $\mathrm{H}$. pylori to clarithromycin before this antibiotic is introduced for treatment.

\section{A:22 ACTIVATION OF METRONIDAZOLE IN HELICOBACTER PYLORI}

M.A. Jorgensen, S.L. Hazell, G.L. Mendz, J. Manos. The University of New South Wales, Sydney, Australia

Objective: The mode of action of metronidazole in anaerobic organisms that are sensitive, is well established - the nitro group of metronidazole is reduced, resulting in products which cause DNA damage and subsequent cell death. $H$. pylori requires up to $5 \%$ oxygen for growth; under these conditions oxygen may convert reduced metronidazole back to the parent compound, with a concomitant production of superoxide. This process is called futile cycling. It is unknown if metronidazole is reduced in $H$. pylori, or if futile cycling and the subsequent production of reactive oxygen radicals are responsible for cell death. In this study, we observed the effects of metronidazole on catalase positive and spontaneous catalase negative mutants of $H$. pylori to determine which process is responsible for cell death.

Methods: Spontaneous catalase negative mutants were obtained by continuous passaging of a number of isolates until a loss of catalase activity was exhibited. The minimal inhibitory concentration (MIC) of metronidazole on catalase positive and catalase negative isolates was determined by the E-test. Resistance to metronidazole was induced by passaging each isolate in the presence of sub-inhibitory concentrations of metronidazole. Metronidazole metabolism was followed in sensitive and resistant isolates by ${ }^{14} \mathrm{~N}-\mathrm{NMR}$ spectroscopy.

Results: Strain RU1 was found to mutate to the catalase negative phenotype. Catalase positive and negative isolates displayed identical MIC values of $0.25 \mu \mathrm{g} / \mathrm{mL}$. NMR spectroscopy revealed that the nitro moiety of the imidazole ring was reduced by sensitive cells. Resistant cells did not reduce metronidazole.

Conclusion: Our results indicate that the mode of action of metronidazole on $\mathrm{H}$. pylori is not mediated via the accumulation of reactive oxygen species as a result of futile cycling, as a lack of catalase activity would make the isolate more sensitive to the reactive products of futile cycling. Rather, the activation of metronidazole by reduction of the nitro moiety may be crucial for initiating its activity in $H$. pylori. Resistance to metronidazole may be mediated by mechanisms that prevent the reduction of metronidazole.

\section{A:23 BACTERICIDAL ACTIVITY OF LANSOPRAZOLE VERSUS OMEPRAZOLE IN VITRO}

K. Vogt, H. Hahn. Dept. of Microbiology, Virchow Hospital, Humboldt University of Berlin, Germany

Proton Pump Inhibitors are known to inhibit growth of H. pylori in higher concentrations. We investigated the killing kinetics of the bactericidal activity of lansoprazole and omeprazole in vitro.

$25 \mathrm{H}$. pylori strains were investigated, 24 patients' isolates and one reference strain (NCTC 11637). Minimum inhibitory concentrations were assessed for both substances by employing the agar dilution method. In 23 strains, the MIC of lansoprazole was 1 to 3 dilution steps lower than the MIC of omeprazole. Six strains were selected for the killing curve experiments. A bacterial inoculum of approx. $10^{8} \mathrm{CFU} / \mathrm{ml}$ was incubated in different concentrations of the two proton pump inhibitors 
diluted in Mueller Hinton broth under constant rotation (100 rpm) in a microaerophilic atmosphere. Specimens were taken at $0 \mathrm{~h}, 4 \mathrm{~h}$, and $24 \mathrm{~h}$ in order to assess the number of viable bacteria.

There was a dose-dependent inhibition of bacterial growth by both proton pump inhibitors at $24 \mathrm{hrs}$, lansoprazole being much more effective than omeprazole. No effect was noted at $4 \mathrm{hrs}$.

Thus proton pump inhibitors may have a synergistic effect in triple therapy regimens which attempt to eradicate $H$. pylori.

\section{A:24 A NEW PHARMACOKINETIC IN VITRO MODEL, DEVELOPED ON INTRACELLULAR H. PYLORI}

R. Rigo, K. Hultén, I. Gustafsson, L. Engstrand. Depts. of Clinical Microbiology and Cancerepidemiology, University Hospital, Uppsala, Sweden

Introduction In vitro models are used to study the effect of antibiotics on microorganisms. Most investigations are performed in broth culture or on agar plates, but kinetic models for bacteria in broth, have been described by several authors. We present a new kinetic model, with emphasis on intracellular pathogens.

Materials and methods A glass chamber, with a metal rack fitting Falcon ${ }^{\circledR}$ cell culture inserts, was connected to a pump by two santoprene tubes. Different tube diameters and pumpspeeds were evaluated and the assay was set up to mimic the half-life of the antibiotic in vivo, i.e. 11 $\mathrm{h}$ for azithromycin and $1 \mathrm{~h}$ for amoxycillin. HEp-2 cells were cultured directly in the inserts and after two days of growth $H$. pylori was added (clinical strain 88-23). Internalization was allowed for $18 \mathrm{~h}$ whereafter extracellular $H$. pylori were eradicated with gentamicin. The inserts were moved to the glass chamber which contained medium with $12.5 \mathrm{mg} / \mathrm{l}$ of either azithromycin (Az) or amoxycillin (Am). Samples were taken at 0 , 2, 4, 6, 8 and $24 \mathrm{~h}$. Cells were lysed and intracellular bacteria counted by culture. Controls (Co), i.e inserts with infected cells in medium without antibiotic supplement, were included at each time interval.

Results A $2 \log _{10}$ reduction of $H$. pylori was achieved in the experiments with azithromycin, while merely no intracellular effect was observed when amoxycillin was used. The antibiotic concentrations at the different time intervals were $12.5,10.0,9.5,8.0,7.0$ and $1.0 \mathrm{mg} / \mathrm{l}$ respectively for azithromycin and $12.5,3.2,0.78,0.20,0.049$ and $0 \mathrm{mg} / \mathrm{f}$ for amoxycillin.
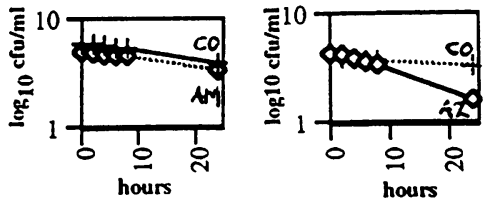

Conclusion This new model is easy and straightforward. It gives a better understanding of the interaction between antibiotics, bacteria and cells. We believe this model is a useful tool in the search for effective treatment strategies, especially against microorganisms with capacity of intracellular growth.

\section{A:25 ERADICATION OF INTRACELLULAR HELICOBACTER PYLORI IN MULTIDRUG RESISTANT MONOCYTES USING AZITHROMYCIN AND LANSOPRAZOLE}

R. Rigo, M. Holmberg, L. Engstrand. Dept. of Clin. Microbiology, Uppsala, Sweden

Background: A major clinical problem in the management of malignancies is primary and aquired resistance to cytotoxic therapy. Classical multidrug resistance (MDR) is mediated by increased expression of a transmembrane $170 \mathrm{kDa}$ glycoprotein which acts as a transporter of drugs out of the cells. An additional effect is that some antibiotics with intracellular activity are transported out of the cells by this mechanism.

The aims of the present study were to investigate whether azithromycin, with known intracellular activity against Helicobacter pylori, becomes less active when the bacteria are inside MDR monocytes compared to non-MDR cells. Furthermore, the possible role of lansoprazole as an inhibitor of this mechanism was studied.

Material and methods: $H$. pylori, strain 88-23, and three cell lines with different MDR phenotypes was used. The cells were infected by $H$. pylori and after $12 \mathrm{~h}$, extracellular bacteria were eradicated with gentamicin. The cells were divided in three groups, with medium containing lansoprazole ( 2 $\mathrm{mg} / \mathrm{l})$, azithromycin $(10 \mathrm{mg} / 1)$ or both, and one control group with RPMI medium only. After 0,4 and $24 \mathrm{~h}$ two samples from each group and cell line was analyzed for intracellular survival of $H$. pylori.

Results and conclusion: Azithromycin had a reduced effect on $H$. pylori residing in the two resistant cell lines, compared to the sensitive cell line. When lansoprazole was added, this resistance was totally inhibited.
Lansoprazole alone had no effect on the bacteria. To sum up, lansoprazole seems to inhibit the protein responsible for transport of antibiotics out of MDR cells.

\section{A:26 DNA TRANSFER IN HELICOBACTER PYLORI}

E.J. Kuipers, D.A. Israel, M.J. Blaser. Vanderbilt University School of Medicine and VA Medical Center, Nashville, Tennessee, USA

There are three known mechanisms by which bacteria can exchange DNA: transformation, transduction and conjugation. Many strains of Helicobacter pylori are naturally competent for transformation in vitro. It is unknown whether $H$. pylori is capable of either transduction or conjugation. Since there is a high degree of genetic variation among strains of $H$. pylori, we sought to determine whether methods of DNA exchange other than transformation exist in $H$. pylori.

We used $H$. pylori strains HPK 1 and HPK5/pHP1 resistant to kanamycin $(\mathrm{K})$, spectinomycin (Sp), rifampicin (R) and/or streptomycin (S). Specifically, the strains examined were HPK1 $\left(K^{S} S^{S} S^{R} R^{R}\right)$ and HPK5/pHP1 $\left(K^{R} S^{R} S^{S} R^{S}\right)$. These two strains were cocultured on non-selective agar plates. After overnight incubation, the cells were transferred to plates containing Sp and S, to select for bacteria possessing a marker from each parent while prohibiting growth of the parental strains. Since transformation is a DNase-sensitive phenomenon, additional experiments were done in the presence of $230 \mu \mathrm{g} / \mathrm{ml}$ DNase.

In each experiment, this procedure yielded progeny with the markers of both parents $\left(\mathrm{S}^{\mathrm{R}} \mathrm{Sp} \mathrm{p}^{\mathrm{R}}\right)$. Control experiments in which the strains were plated separately did not yield any cells that were $S^{R} S p^{R}$, indicating that the progeny obtained from the mating were not the result of spontaneous mutation. In one DNase experiment, the $S^{R} S p^{R}$ progeny were subsequently shown to be $K^{S}$, suggesting directionality of DNA transfer. The addition of DNase resulted in 60-90\% fewer colonies than matings without DNase, but did not eliminate development of dually resistant progeny in these experiments. Control experiments with the same strains and chromosomal DNA from a chloramphenicol-resistant strain did not yield transformants in the presence of the same DNase concentration. These experiments suggest that both a DNase-sensitive mechanism (transformation) as well as a DNase-resistant mechanism may contribute to the transfer of DNA between $H$. pylori cells.

\section{A:27 ACHLORHYDRIC POTENTIATION OF ANTIBIOTIC ACTIVITY IN MICE COLONISED WITH H. PYLORI}

A. McColm, J. Bagshaw. GlaxoWellcome Research and Development, Stevenage, SGI 2NY, UK

The in vivo activities of a range of anti-Helicobacter antibiotics were compared under normal and achlorhydric conditions using a mouse model of gastric $H$. pylori colonisation. Achlorhydria was generated by predosing animals with the long acting $\mathrm{H}_{2}$ antagonist, loxtidine $(100 \mathrm{mg} / \mathrm{kg}$ p.o.) 30 minutes prior to each compound dose (b.d $\times 4$ p.o.). The activity of all compounds was markedly enhanced by several fold in achlorhydric mice. For example, in normal mice, doses of clarithromycin greater than 25 $\mathrm{mg} / \mathrm{kg}$ were required for $100 \%$ eradication while approximately $5 \mathrm{mg} / \mathrm{kg}$ was fully effective in achlorhydric mice. The activity of compounds administered parenterally was also enhanced by orally generated achlorhydria. Measurement of gastric $\mathrm{pH}$ values confirmed that loxtidine treatment, administered as above, elevated the $\mathrm{pH}$ of the mucosa to a mean value of 5.6 compared to approximately 3 for control stomachs. Ranitidine was less effective at both affecting stomach $\mathrm{pH}$ and enhancing drug action. This potentiation of antibiotic efficacy by loxtidine was also observed in the fer$\mathrm{ret} / H$. mustelae model but was less pronounced. Although, 4 days therapy with loxtidine alone showed no apparent effects on $H$. pylori colonisation in mice, extending the duration of treatment to 35 days resulted in a marked loss of bacteria $-40 \%$ mice colonised compared to $90 \%$ in controls. The action of loxtidine, which has no intrinsic anti-H. pylori activity (MIC > $1000 \mu \mathrm{g} / \mathrm{ml}$ ), was dose related in nature and probably reflects a detrimental effect of local $\mathrm{pH}$ changes on $H$. pylori growth in vivo rather than alterations in the stability or bio-availability of the test compounds.

\section{A:28 OMEPRAZOLE (OME) AFFECTS GASTRIC JUICE CONCENTRATIONS OF METRONIDAZOLE (MET) FOLLOWING ORAL DOSING}

M. Kareemi, P.T. Pollak, S.J.O. Veldhuyzen van Zanten. Dalhousie University, Halifax, Canada

It is unclear whether antibiotics achieve Hp eradication by a topical effect as they pass through the stomach or whether absorption in the small bowel and subsequent secretion across gastric mucosa into gastric juice is required. We measured gastric and serum MET concentrations ([MET]) 
before and after OME. Four healthy Hp-negative volunteers received a single MET $500 \mathrm{mg}$ tablet. Gastric juice samples were aspirated by NG-tube every $15-60 \mathrm{~min}$ for $8 \mathrm{~h}$. Serum samples were obtained at the same times. The same protocol was repeated after 7 days OME $20 \mathrm{mg}$ bid, which raised gastric $\mathrm{pH}$ from $<1.5$ to $>4$. [MET] (total and non-ionized) were measured using a validated HPLC method.

Gastric juice results are plotted at right. Total [MET] was very high Pre OME treatment and non-ionized [MET] was low. Post OME, all [MET] was non-ionized ( $=$ total MET) and peaked about $50 \%$ lower. Serum [MET] (not shown) increased much more rapidly in the first hour Post OME.

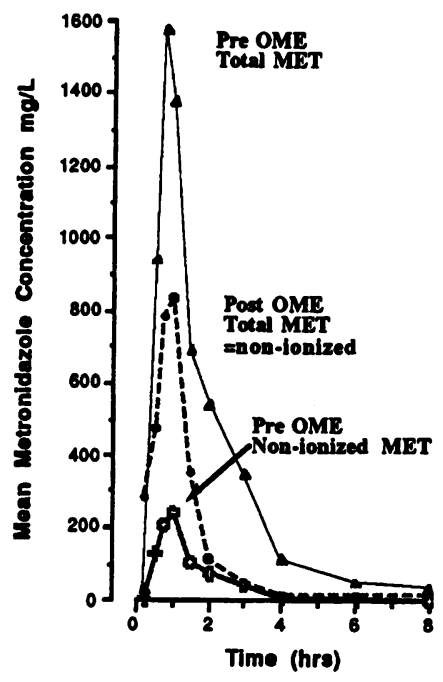

OME leads to an increase in non-ionized [MET] which more easily crosses the gastric mucosa. This appears to favor early diffusion of MET into serum reducing the accumulation of gastric juice [MET]. However organisms in the stomach would be exposed to much higher non-ionized MET concentrations post OME. This should favor eradication of $\mathrm{Hp}$.

\section{A:29 OMEPRAZOLE (OME) DOES NOT AFFECT GASTRIC JUICE CONCENTRATIONS OF NON-IONIZED METRONIDAZOLE (MET) FOLLOWING INTRAVENOUS METRONIDAZOLE} ADMINISTRATION

P.T. Pollak, S.J.O. Veldhuyzen van Zanten. Dalhousie University, Halifax, Canada

We have shown that iv MET moves from serum into the gastric lumen. OME $20 \mathrm{mg}$ bid markedly reduced gastric juice MET concentrations. The explanation for this decrease is not documented. We studied 4 healthy volunteers who received an iv bolus of $500 \mathrm{mg}$ MET. Gastric juice was aspirated by NG-tube every 15-60 min over $8 \mathrm{~h}$. Protocol was repeated after 7 days OME $20 \mathrm{mg}$ bid, which increased gastric $\mathrm{pH}$ from $<2$ to $>$ 6. Total MET concentrations were measured in serum/gastric juice by a validated HPLC method. Total and non-ionized MET were compared.
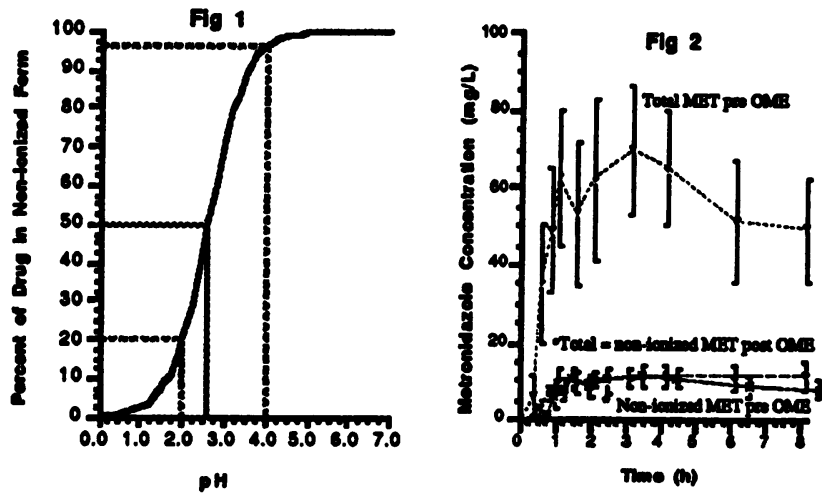

Fig. 1 shows that for a weak base (MET) with pKa 2.6, $<20 \%$ is in the non-ionized form at $\mathrm{pH}<2$, while this is $>95 \%$ at $\mathrm{pH}>4$. Only non-ionized drug freely diffuses across the gastric mucosa and penetrates Hp organisms. In gastric juice $(\mathrm{pH}<2)$ most MET is rapidly converted to the ionized form. Despite markedly decreased total MET in gastric juice following OME, concentrations of non-ionized MET remain the same (Fig. 2). This is because non ionized MET is the form in equilibrium with serum MET and the same concentrations of non-ionized MET accumulate at any gastric pH. At low pH, it is the "trapping" of MET in ionized form that causes a high total MET (total MET > non-ionized MET). Post OME at gastric $\mathrm{pH}>4$, all MET crossing the mucosa remains uncharged and there is no "trapping" (total = non-ionized). Therefore, following iv MET, OME does not alter the amount of non-ionized MET to which Hp would be exposed in gastric juice.

\section{A:30 EFFECT OF THE ALUMINUM-MAGNESIUM CONTAINING ANTACID RIOPAN ON THE PENETRATION OF AMOXICILLIN AND CLARITHROMYCIN THROUGH GASTRIC MUCUS}

P. Grübel, D.R. Cave. Division of Gastroenterology, St. Elizabeth's Medical Center, Boston MA, USA

Background: The lack of clinical efficacy in the antibiotic treatment of Helicobacter pylori may be caused by the inability to reach the bacteria within the highly viscous gastric mucus layer. The aim of our study was to determine the effectiveness of amoxicillin and clarithromycin in penetrating gastric mucus. The two clinical formulations of the antacid magaldrate (Riopan gel and powdered tablets) have been also studied in regard to their effects on antibiotic penetration of gastric mucus.

Methods: Permeability was monitored by measuring diffusion of antibiotics across solutions of semipurified pig gastric mucin (PGM) with and without added antacid, and buffer solutions at $\mathrm{pH} 4$ and 7 using a microfiltration device and an agar diffusion bioassay method.

Results: Gastric mucus retarded the penetration of amoxicillin and clarithromycin significantly by $90 \%(\mathrm{p}<0.001)$. Clarithromycin penetrated at a ten-fold higher rate through mucus than amoxicillin $(\mathrm{p}<0.05)$. At $\mathrm{pH} 7$, Riopan tablets increased the penetration rate of amoxicillin through PGM more than 3-fold $(p<0.05)$, whereas they did not effect the penetration of clarithromycin. In contrast, Riopan gel reduced the penetration rate of clarithromycin by $63 \%(\mathrm{p}<0.05)$ at $\mathrm{pH} 7$ and $77 \%(\mathrm{p}<0.05)$ at $\mathrm{pH} 4$, but did not effect the penetration of amoxicillin.

Conclusions: Gastric mucus retards antibiotic penetration drastically. The superior penetration of clarithromycin over amoxicillin may be one factor explaining its higher clinical efficacy. The two clinical formulations of the antacid magaldrate show two opposite new effects on mucus penetrability to antibiotics, which may influence the outcome of $H$. pylori eradication.

\section{A:31 TRANSFER OF PENICILLINS ACROSS GASTRIC MUCOSA -} IMPACT OF PROTEIN BINDING

A.F. Goddard, P.O. Erah, P.N. Shaw, D.A. Barrett, R.C. Spiller. University of Nottingham, Nottingham, UK

Background Lack of resistance by $H$. pylori to penicillins makes them an attractive therapeutic option. However, results with different penicillins have been poor, perhaps because of failure of systemic drug to penetrate the gastric mucosa.

Aims To investigate the principles governing gastric mucosal flux of different penicillins.

Methods Gastric mucosal flux (nmol.hr- ${ }^{-1} . \mathrm{cm}^{-2}$ ) was assessed using a previously validated Ussing chamber method. $1 \mathrm{mM}$ solution of penicillin was placed on the serosal side of rat gastric mucosa and the flux ( \pm SEM) measured over $60 \min (n=8$ for each penicillin). The flux of each penicillin was compared with amoxycillin, and the relationship of flux with protein binding, expressed as fraction unbound, and lipophilicity, expressed as $\log \mathrm{D}$ at $\mathrm{pH} 7.4$, assessed using non-parametric analysis.

Results

\begin{tabular}{llcl}
\hline & Flux & Log D & Fraction unbound \\
\hline Amoxycillin & $2.78(0.31)$ & -1.89 & 0.83 \\
Ampicillin & $2.80(0.27)$ & -2.25 & 0.82 \\
Cyclacillin & $1.94(0.32)$ & -2.54 & 0.80 \\
Carbenicillin & $1.51(0.25)^{*}$ & $>-2.5$ & 0.53 \\
Penicillin V & $0.89(0.17)^{* *}$ & -2.73 & 0.21 \\
Phenethicillin & $0.66(0.03)^{* *}$ & $>-2.5$ & 0.25 \\
Propicillin & $0.83(0.16)^{* *}$ & -1.85 & 0.10 \\
\hline
\end{tabular}

${ }^{*} \mathrm{P}<0.01,{ }^{* * P}<0.001$ compared with amoxycillin. Flux was correlated $(\mathrm{P}<0.02)$ with protein binding but not lipophilicity.

Conclusions In vitro flux of aminopenicillins across gastric mucosa is greater than monobasic penicillins, due to lower protein binding within the tissue, perhaps explaining differences in efficacy against $H$. pylori in vivo.

\section{A:32 CLARITHROMYCIN SUSCEPTIBILITY TESTING BREAKPOINTS FOR HELICOBACTER PYLORI}

L.J. Utrup ${ }^{1}$, S.K. Tanaka ${ }^{2}$, C.A. Olson ${ }^{2}$, D.Y. Graham ${ }^{3} .{ }^{1}$ Food and Drug Administration, Rockville, MD; ${ }^{2}$ Abbott Laboratories, Abbott Park, IL; ${ }^{3}$ VAMC and Baylor College of Medicine, Houston, TX, USA

Introduction: Susceptibility testing of $H$. pylori during pre- and post- 
treatment phases of clinical trials is important to assess pretreatment resistance and emergence of resistance.

Patients - Methods: During two U.S. clarithromycin plus omeprazole trials for the treatment of active duodenal ulcers, susceptibility testing was performed using a broth microdilution minimum inhibitory concentration (MIC) methodology (Diagn Microbiol Infect Dis. 1996; 24: 37-41).

Results: Of the $104 \mathrm{H}$. pylori isolates collected during pretreatment visits, 98 were susceptible, two were intermediate and four were resistant to clarithromycin. Of the 98 patients who had susceptible isolates pretreatment, 72 were $H$. pylori negative and 26 were $H$. pylori positive post-treatment. $H$. pylori from 25 of these 26 patients became resistant to clarithromycin. All six patients with intermediate or resistant isolates pretreatment had resistant strains post-treatment.

Conclusions: Tentative clarithromycin MIC breakpoints were established as susceptible $\leq 0.06$, intermediate $0.12-2.0$, and resistant $\geq 4.0$ $\mu \mathrm{g} / \mathrm{mL}$ for $H$. pylori isolates from patients treated with clarithromycin plus omeprazole. The correlation between MIC results and clinical outcome was very good using the methodology and breakpoints indicated above. Adjustments in the breakpoints may be appropriate when different testing or treatment regimens are used or standardized methods become available.

\section{A:33 SUSCEPTIBILITY TEST MEDIUM AFFECTS DETECTION OF ANTIBIOTIC RESISTANCE IN H. PYLORI}

P.D. Midolo, J.R. Lambert, J.M. Bell, J.D. Turnidge, M.L. Grayson. Microbiology and Infectious Diseases, Monash Medical Centre, and Gastroenterology Research Group, Mornington Peninsula Hospital, Melbourne, Victoria, Australia

Natural and acquired resistance in $H$. pylori to nitroimidazoles and macrolides has recently been shown to be increasing over time. Resistance to these antimicrobials can adversely affect treatment success. Surveillance of local resistance rates in $H$. pylori by standardised methods is necessary to optimise treatment selection and outcome.

Aim: To investigate the influence of susceptibility test media on the in vitro susceptibility of $H$. pylori to nitroimidazoles and macrolides.

Materials and Methods: The Etest has been recommended as a reference method for $H$. pylori susceptibility testing. Etest strips were used to determine MICs for metronidazole and clarithromycin. Forty four recent pre-treatment $H$. pylori isolates were tested on: Columbia agar base with $5 \%$ whole horse blood (HBA); Mueller-Hinton agar with 5\% whole horse blood (MHA); and Wilkins-Chalgren agar with 5\% whole horse blood (WCA). A suspension of organisms was made in brain heart infusion broth to a $1 \mathrm{McFarland}$ equivalent $\left(7 \times 10^{7} \mathrm{CFU} / \mathrm{ml}\right)$. This suspension was swabbed onto each media. On each plate was placed either a metronidazole or a clarithromycin Etest strip. MICs were read after $72 \mathrm{hrs}$ incubation at $35^{\circ} \mathrm{C}$ in a microaerobic atmosphere (Camp Gas Pak, Oxoid). Resistance was defined as $>8 \mathrm{mg} / \mathrm{L}$ for metronidazole and $>0.5 \mathrm{mg} / \mathrm{L}$ for clarithromycin.

Results: All isolates grew equally well on each medium when inspected visually. By non-parametric statistical testing, MIC values were significantly different for metronidazole (HBA $<$ MHA $<$ WCA). Twenty four strains were resistant on all three media $(55 \%)$ while an additional strain was resistant on WCA. Only minor differences in MICs were seen with clarithromycin with no significant difference between MHA and WCA.

Conclusions: Test medium affects $>$ in vitro susceptibility of $H$. pylori particularly against metronidazole. The effect is possibly due to different diffusion rates of antibiotic in the media or variation in the growth of the organisms tested. HBA plates should not be used to test $H$. pylori against metronidazole as resistance will be underestimated compared to MHA or WCA. Global surveillance of $H$. pylori resistance necessitates the use of a single standardised test medium.

\section{A:34 THE KILLING OF HELICOBACTER PYLORI IN VITRO BY PROTON PUMP INHIBITORS AND ANTIBIOTICS}

P.D. Midolo, J.R. Lambert, J.D. Turnidge, J.M. Bell, M.L. Grayson. Department of Microbiology and Infectious Diseases, Monash Medical Centre, Clayton and Gastroenterology Research Group, Mornington Peninsula Hospital, Frankston, Victoria, Australia

Antimicrobial therapy is now commonly used to cure $H$. pylori infection. Single agents are effective in vitro at killing $H$. pylori but eradication of the organism in patients with single agents is poor. Time-kill curves using achievable in vivo drug concentrations measuring bactericidal activity over time may reveal differences in the effects of antimicrobials against $\boldsymbol{H}$. pylori despite similar activities as measured by MIC.

Aim: To investigate the B-lactam amoxycillin and the macrolide erythromycin in combination with the proton pump inhibitors (PPIs) omeprazole and lansoprazole for bactericidal and synergistic activity against $\boldsymbol{H}$. pylori.
Materials and Methods: Wilkins-Chalgren anaerobe broth with $0.5 \%$ cyclodextrin cultures of $H$. pylori NCTC 11637 , clinical isolate M98 and H. mustelae ATCC 43773 were examined over 24 hrs. Bactericidal activity of amoxycillin, erythromycin and the 2 PPIs was examined by comparing the $1 \times, 5 \times$ and $10 \times$ MIC concentrations determined by agar dilution or Etest. Serial dilutions were made in PBS and viable counts were performed on horse blood agar incubated in $5 \% \mathrm{CO}_{2}$ for 7 days. The broth cultures were maintained in microaerobic conditions (GasPak, Oxoid) with constant agitation at $35^{\circ} \mathrm{C}$. Only dilution plates giving a readable count of $<50$ colonies per drop were recorded with the limit of detection for the assay being $13 \mathrm{CFU} / \mathrm{mL}$. Synergy studies were performed at $1 \times$ MIC only.

Results: All drugs except amoxycillin showed marked concentration dependent killing of $H$. pylori. Erythromycin was the most active with a $6 \log _{10}$ decrease in viable count at $5 \times$ MIC within $6 \mathrm{hrs}$ of contact. Lansoprazole at 10x MIC gave this degree of killing at $6 \mathrm{hrs}$ whereas omeprazole caused only a $3 \log _{10}$ decrease in viable count by this time. All drugs including the PPIs had similar bactericidal activity against $H$. mustelae as for $H$. pylori. Neither PPI in combination with amoxycillin produced complete killing of $H$. pylori over the $24 \mathrm{hr}$ test period for the type strain or the clinical isolate. With erythromycin, a $>3 \log _{10}$ decrease in viable count with lansoprazole and a $2 \log _{10}$ decrease with omeprazole occurred at $6 \mathrm{hrs}$ exposure indicating some degree of synergy.

Conclusions: Combinations of PPI and antibiotic show additive/synergistic activity to varying degrees. The little used antibiotic erythromycin in combination with a PPI should be investigated for clinical effectiveness with various dosing schedules to maximise eradication of $H$. pylori from infected individuals.

\section{A:35 ASSOCIATION OF CLARITHROMYCIN SENSITIVITY TEST RESULTS WITH ERADICATION OF HELICOBACTER PYLORI}

\section{Tompkins, J. Perkin, C. Smith. Public Health Laboratory, Leeds UK}

Purpose. To ascertain the clinical value of sensitivity tests of $H$. pylori (Hp) to clarithromycin (CL) and to compare methods of testing. Methods. In a multicentre study CL (500 mg $\times 3$ daily) and omeprazole (40 mg once daily) were used in a 14 day regimen. Eradication was confirmed at 4-6 weeks by $13 \mathrm{C}$-Urea Breath Test. Pre-treatment sensitivities on antral isolates of $\mathrm{Hp}$ were carried out using $\mathrm{E}$ tests (131 patients) and also $2 \mathrm{mcg}$ discs (114). Isolates were also used to compare $\mathrm{E}$ test and disc sensitivities to metronidazole. Post-treatment isolates from 20 patients were also exam ined for CL resistance and compared with pre-treatment results. Results $\mathrm{Hp}$ was eradicated in 101 patients (100 sensitive to $C L(S), 1$ resistant (R)) and persisted in $30(26 \mathrm{~S}, 4 \mathrm{R})$ giving a positive predictive value (pv) of $79 \%$ and negative pv of $80 \%$. There was complete agreement between $E$ test and disc sensitivities to $\mathrm{CL}$. There was disagreement between $\mathrm{E}$ test and disc for 9/114 metronidazole results. Comparing pre and post treatment CL results, 5S remained $S, 9 S$ became $R, 2 R$ remained $R$ and in 4 cases data were incomplete. Conclusion. Sensitivity tests to $\mathrm{CL}$ are of clinical value, and disc diffusion tests are as reliable as E Tests.

\section{A:36 SUSCEPTIBILITY TO METRONIDAZOLE AND CLARITHROMYCIN AMONGST HELICOBACTER PYLORI CLINICAL ISOLATES FROM THE SAME PATIENT}

T. Alarcón, D. Domingo, I. Sánchez, J.C. Sanz, M. López-Brea. Dep. of Microbiology, Hospital de la Princesa, Madrid, Spain

Results of the in vitro metronidazole and clarithromycin susceptibility tests are found to be of value in predicting the outcome of the $H$. pylori eradication regimens.

Purpose: The aim of this study was to detect the resistance to metronidazole and clarithromycin in isolates obtained from antrum and corpus samples during the same endoscopy in 18 patients.

Methods: $44 \mathrm{H}$. pylori clinical isolates were obtained from 18 patients ( 2 or 3 samples from each patient: one sample from corpus and 1 or 2 from antrum). Samples were cultured and $H$. pylori identified following standard procedures. The resistance was detected by an agar dilution method. Muieller Hinton agar supplemented with $7 \%$ lysed horse blood was used. The microorganisms were grown in BHI $+10 \%$ foetal calf serum for $48 \mathrm{~h}$ and inoculated using a Steer replicator. Plates were incubated 2 to 5 days at $35^{\circ} \mathrm{C}$ in a $\mathrm{CO}_{2}$ incubator and resistance was considered when MIC $\geq 8 \mathrm{mg} / \mathrm{l}$ for metronidazole and $\geq 4 \mathrm{mg} / 1$ for clarithromycin.

Results: In all the isolates of the same patient the results were similar for clarithromycin (2 patients with resistant isolates and 16 patients with susceptible isolates). Not all the isolates from the same patient were similar in the metronidazole susceptibility. In 5 patients all the isolates were metronidazole resistant and in 11 were metronidazole susceptible. However, in 2 patients the isolates from the antrum were susceptible, while the isolate from the corpus were metronidazole resistant.

Conclusions: According to these results, clinical isolates from antrum 
and corpus of the same patient have to be tested in order to detect metronidazole and clarithromycin resistance.

\section{A:37 METRONIDAZOLE AND CLARITHROMYCIN SUSCEPTIBILITY AMONGST H. PYLORI CLINICAL ISOLATES FROM DIFFERENT SPANISH REGIONS}

M. López-Brea, D. Domingo, I. Sánchez, J.M. Hernandez, H. Villar, T. Alarcón. Dep. Microbiology, Hospital de la Princesa, Madrid, Spain; Hosp. Inmaculada, Almeria, Hosp. San Agustín, Asturias, Spain

Clarithromycin and metronidazole are the most frequent antimicrobial agents used for Helicobacter pylori infection. Resistance to metronidazole has been reported with several rates, depending on the population studied.

Purpose: to determine the metronidazole and clarithromycin resistance rate in $\mathrm{H}$. pylori clinical isolates from three different regions of Spain.

Methods: $171 \mathrm{H}$. pylori strains isolated from patients with digestive diseases were studied (56 from the South, 68 from North and 47 from the Centre). Patients previously treated for eradication of $H$. pylori were not included. The resistance was detected by an agar dilution method. Müeller Hinton agar supplemented with $7 \%$ lysed horse blood was used. Plates were incubated 2 to 5 days at $35^{\circ} \mathrm{C}$ in a $\mathrm{CO}_{2}$ incubator and resistance considered when MIC $\geq 8 \mathrm{mg} /$ for metronidazole and $\geq 4 \mathrm{mg} /$ for clarithromycin.

Results: The percentage of resistance is included in Table:

\begin{tabular}{lllll}
\hline & South & North & Centre & Total \\
\hline No. strains & 56 & 68 & 47 & 171 \\
Metronidazole & $21.4 \%$ & $14.7 \%$ & $46.8 \%$ & $25.7 \%$ \\
Clarithromycin & $5.3 \%$ & $0 \%$ & $14.9 \%$ & $5.8 \%$ \\
\hline
\end{tabular}

Conclusions: The overall rate of resistance to metronidazole $(25.7 \%)$ is higher than to clarithromycin (5.8\%) and was different in the three regions tested. Due to this fact it is important to determine the resistance rate in several populations even from the same country.

\section{A:38 COMPARISON OF SUSCEPTIBILITY TESTING METHODS FOR CLARITHROMYCIN MIC DETERMINATIONS OF HELICOBACTER PYLORI}

D. Shortridge ' , R.K. Flamm ', J. Beyer ${ }^{1}$, D. Graham ${ }^{2}$, J. Versalovic ${ }^{2}$,

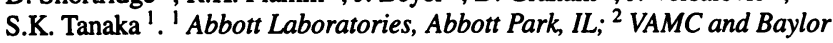
College of Medicine, Houston, TX, USA

Three susceptibility testing methods were used to determine the clarithromycin MIC of over 100 pretreatment isolates of $H$. pylori collected during a recent US clinical treatment trial. The methods used were: agar dilution using Mueller Hinton agar plus 5\% horse blood, microtiter broth dilution using brain heart infusion broth supplemented with $10 \%$ horse serum and $0.25 \%$ yeast extract and Etest (AB Biodisk) on Mueller Hinton agar containing $5 \%$ sheep blood. The effect of medium $\mathrm{pH}$ on agar dilution clarithromycin MIC values was also compared. All testing was done in $12 \% \mathrm{CO}_{2}$ at $37^{\circ} \mathrm{C}$.

\begin{tabular}{lllll}
\hline $\mathrm{n}=113$ & \multicolumn{4}{l}{ Clarithromycin MIC $(\mu \mathrm{g} / \mathrm{ml})$} \\
\cline { 2 - 5 } & Etest & Broth & Agar pH 8 & Agar pH unadjusted \\
\hline MIC $_{50}$ & 0.016 & 0.016 & 0.03 & 0.12 \\
MIC $_{90}$ & 0.06 & 0.03 & 0.06 & 0.12 \\
\hline
\end{tabular}

Etest and the microbroth method compared very well, with $88 \%$ of MIC values within one twofold-dilution of each other. Agar dilution, in which the agar had been adjusted to $\mathrm{pH} 8$, also compared well with Etest $(85 \% \pm$ 1 dilution) and broth (79\% \pm 1 dilution) methods. The method that agreed the least with the other three was agar dilution without $\mathrm{pH}$ adjustment of the medium. Only $6 \%$ of the MIC values determined by unadjusted agar were within one dilution of microbroth values. Unadjusted Mueller Hinton agar has a pH of 7.2-7.4. Following incubation in $12 \% \mathrm{CO}_{2}$ the medium $\mathrm{pH}$ decreases to 6.8-7.0. Decreased $\mathrm{pH}$ has been shown to increase the in vitro MIC of macrolide antibiotics including clarithromycin. Since $H$. pylori requires high levels of $\mathrm{CO}_{2}$ for growth, it is important to consider the effect of medium $\mathrm{pH}$ changes caused by the growth environment. Etest, broth microdilution and agar $\mathrm{pH} 8.0$ all provide comparable MIC results for susceptibility testing of $\boldsymbol{H}$. pylori, although each method may require different interpretive criteria.

\section{A:39 SUSCEPTIBILITY OF H. PYLORI IN CANADA TO CLARITHROMYCIN AND METRONIDAZOLE}

L.M. Best, D.J.M. Haldane, S.J.O. Veldhuyzen van Zanten. Queen Elizabeth II Health Sciences Center, VGH, Halifax, NS, Canada

Resistance to antimicrobial agents is a major determinant of the efficacy of regimens to eradicate $H$. pylori. Clarithromycin (CLA) and Metronidazole (MET) are widely used in triple therapy combinations. The aim of this study was to determine the rate of primary resistance to CLA and MET in $H$. pylori isolated from patients in our population. 77 strains of $H$. pylori recovered from infected patients prior to treatment were tested. We used CLA and MET E-tests which have been shown to be reliable for $H$. pylori susceptibility testing. Mueller Hinton agar with $7 \%$ sheep blood plates were inoculated with $1 \times 10^{6}$ organisms and E-test strips were applied. After incubation for 4 days at $37^{\circ} \mathrm{C}$ in a microaerophilic atmosphere the plates were read. Control organisms were tested to validate the assay. The results of E-tests were easy to interpret. Strains were considered resistant if the minimum inhibitory concentration (MIC) was CLA $>2 \mu \mathrm{g} / \mathrm{ml}$ and MET $>8 \mu \mathrm{g} / \mathrm{ml}$. One strain was CLA resistant, MIC $12 \mu \mathrm{g} / \mathrm{ml}$, and 76 strains were sensitive. The CLA MIC90 was $0.023 \mu \mathrm{g} / \mathrm{ml}$. The rate of primary resistance was $1.3 \%$. 29 strains were MET resistant, MICs > 32 (22), 12 (5), 8 (2), and 48 strains were sensitive. The MIC90 of the sensitive strains was $4 \mu \mathrm{g} / \mathrm{ml}$. The rate of primary MET resistance was $38 \%$. The rate of CLA resistance is low and MET resistance is high in NS, Canada, and this has implications for the choice of treatment regimens.

\section{A:40 COMPARISON OF E-TEST TO AGAR DILUTION AND BROTH MICRODILUTION METHODS FOR QUANTITATIVE ANTIMICROBIAL SUSCEPTIBILITY TESTING OF HELICOBACTER PYLORI}

R. Piccolomini, G. Di Bonaventura, G. Catamo, C. Picciani, F. Carbone, M. Neri. "G. D'Annunzio" University, Chieti, Italy

Resistance of $H$. pylori to antimicrobial agents is an important factor determining lack of success of anti-H. pylori treatments. Therefore, it would be useful to determine in vitro susceptibility of the bacterium to antimicrobial agents before initiating any anti-H. pylori therapy. Aim of our study was to evaluate E-test, a recently developed commercial kit (AB, Biodisk, Solna, Sweden), for susceptibility testing of clinical isolates of $H$. pylori against 20 different antimicrobial agents and compare the results with those determined by standard agar dilution and broth microdilution methods. Methods: thirty $H$. pylori strains from patients with duodenal ulcer were tested. The E-test method was performed in Mueller-Hinton agar with 5\% sheep blood. Agar dilution method was performed in Mueller-Hinton agar with $5 \%$ sheep. Broth microdilution was performed using Mueller-Hinton broth. For all three methods employed, inoculum of tested strains was adjusted to $4 \mathrm{Mc}$ Farland scale. All plates were incubated in a microaerophilic atmosphere at $35^{\circ} \mathrm{C}$ for up to 5 days. Results: the agreement between MICs by the E-test and the standardized methods was good: 91 and $99.2 \%$ (agar dilution), $90.6 \%$ and $98.3 \%$ (broth microdilution) of results being within, respectively, 1 and $2 \log _{2}$ dilution steps. Thirty percent $(9 / 30)$ of the strains of $H$. pylori tested were resistant to metronidazole, $3 \%(1 / 30)$ to both clarithromycin and tetracycline. Conclusions: we have confirmed that the E-test is comparable to standardized methods for sensibility testing. Therefore, E-test is a simple and reliable method for testing $H$. pylori susceptibility to antimicrobial agents in clinical practice. 